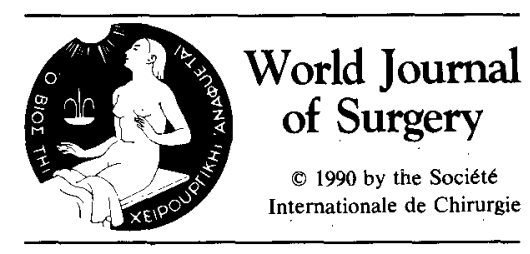

\title{
Stricture and Perforation of the Esophagus: Overlooked Threats in the Zollinger- Ellison Syndrome
}

\author{
Anne-Greth Bondeson, M.D., Ph.D., Lennart Bondeson, M.D., Ph.D., and Norman W. Thompson, M.D. \\ Department of Surgery, University of Michigan Medical Center, Ann Arbor, Michigan, U.S.A.
}

\begin{abstract}
This study was undertaken to assess the frequency of significant esophageal involvement in the Zollinger-Ellison syndrome (ZES). In a consecutive series of 24 patients with this disease, $9(37 \%)$ showed endoscopic evidence of acid-induced esophageal lesions ranging from erosive inflammation to ulceration with massive bleeding, severe stricture formation, and perforation. In 3 cases, pronounced esophagitis was known 1-5 years before the underlying disease was diagnosed. Severe esophageal complications developed despite treatment with antisecretory drugs. It is emphasized that the best way to limit such complications is by excision of the underlying gastrin-secreting tumor(s) when possible.
\end{abstract}

Esophageal involvement by acid-induced disease is an aspect of the Zollinger-Ellison syndrome (ZES) that tends to be overshadowed by other more urgent problems and has received very little attention in the medical literature. It was not until 1979 that an association between ZES and gastroesophageal reflux was suggested [1], and subsequent comments on this subject are few [2-4]. The accumulated experience from a substantial number of ZES patients referred to the University of Michigan Medical Center has shown that gastroesophageal reflux is not only a common and sometimes initial manifestation of the disease, but also a potentially serious threat. The purpose of this report is to emphasize these facts, and to underline that the best way to limit the complications is by excision of the underlying gastrin-secreting tumor(s) when possible.

\section{Material and Methods}

Forty-two patients with ZES were referred to the University of Michigan Medical Center in Ann Arbor from 1962 through 1988. Eighteen patients admitted before 1983 were included in a previous study on esophageal disease from a radiologic point of view [4], and these patients will not be considered further in this report. The additional 24 patients forming the basis of this study

Presented at the International Association of Endocrine Surgeons in Toronto, Ontario, Canada, September, 1989.

Supported by grants from the Swedish Medical Research Council, the Swedish Society of Medicine, the Anders Otto Swärd Foundation, and the Surgery Foundation of Skövde Central Hospital.

Reprint requests: Dr. A.-G. Bondeson, Department of Surgery, Central Hospital, S-541 85 Skövde, Sweden. included 11 women, 12 men, and 1 boy with an age range from 11 to 83 years at the time of diagnosis (median, 46 years). In 3 patients, ZES occurred as part of multiple endocrine neoplasia type I (MEN I). Histologically verified gastrinomas were removed in 15 cases. The primary tumor(s) were located in the pancreas in 6 patients, in the duodenum in 7 patients, and in the liver in 1 patient. A solitary lymph node containing gastrinoma was the only tumor manifestation discovered in 1 patient. In the remaining 9 cases, the diagnosis was based on hypergastrinemia, positive secretin-stimulation test, and hyperchlorhydria. Information regarding signs of esophageal disease was obtained by review of the medical records at the University Hospital in Ann Arbor.

\section{Results}

Endoscopic examination of the esophagus, performed before gastric resection whenever this had been done, was documented in 18 cases. Thirteen of these patients showed evidence of acid-induced esophagitis which was associated with ulcerations in 9 cases. In 3 cases, esophagitis was diagnosed endoscopically 1-5 years before the nature of the underlying disease was realized. Three patients developed severe complications as follows.

A 42-year-old woman had a history of intermittent epigastric pain for many years when she developed symptoms of upper gastrointestinal bleeding. The origin of this appeared to be a duodenal ulcer. At endoscopic examination, it was noted that she also had severe esophagitis. Treatment with cimetidine was started. Three years later, while taking $300 \mathrm{mg}$ of cimetidine 5 times a day, she was admitted as an emergency because of sudden profound weakness, hematemesis, and a hemoglobin of only $7.5 \mathrm{~g}$ percent. Endoscopy revealed an esophageal ulcer to be the source of bleeding, whereas there were no changes but erythema in the duodenum. After blood replacement, the patient was referred to the University Hospital for evaluation of possible ZES and this diagnosis was confirmed biochemically. Her subsequent treatment has been given elsewhere.

A 19-year-old woman was referred to the University Hospital for treatment of malignant gastrinoma with liver metastases. Previous endoscopic examination elsewhere had shown severe 
ulcerating esophagitis in addition to a bleeding duodenal ulcer that led to exploration and discovery of her disease. One year later, while taking cimetidine and antacids, she began treatment with somatostatin analog (201-995) $250 \mathrm{mcg}$ twice a day. After having been on this regimen for 6 months, the patient complained of increasing heartburn and dysphagia. Endoscopy showed persistent severe esophagitis complicated by stricture. This stricture has required repeated dilatations to permit oral alimentation.

A 45-year-old woman with MEN I was admitted to the Division of Endocrinology and Metabolism at the University Hospital where a suspected ZES was confirmed biochemically. Endoscopic examination showed severe esophageal changes with widespread inflammation and multiple ulcers. At the time of admission, the patient was taking ranitidine $150 \mathrm{mg}$ twice a day. This medication was changed to famotidine $40 \mathrm{mg} 4$ times a day. Because of persistent symptoms, somatostatin analog $150 \mathrm{mcg} 3$ times a day was added to her therapeutic program. This reduced her basal acid output to normal levels. Nevertheless, she was readmitted 1 month later because of severe heartburn and dysphagia. Somatostatin analog was increased to $150 \mathrm{mcg} 4$ times a day, and famotidine to $60 \mathrm{mg} 4$ times a day. Furthermore, metoclopramide was added in incremental doses until the patient complained of drowsiness; however, she experienced progressive dysphagia and a $15-\mathrm{kg}$ weight loss during the following 6 weeks. Roentgen examination showed an esophageal stricture with narrowing of the lumen to $5 \mathrm{~mm}$. Subsequently, she underwent several painful dilatations to be able to continue oral alimentation. At this point, surgical advice was requested and the patient was recommended gastrinoma localization studies; however, before this could be done, she vomited, resulting in esophageal perforation and emptying of gastric contents into the chest. The diagnosis was established immediately and emergency esophagectomy and pleural drainage were performed. Exploratory laparatomy was also done at this occasion and 3 duodenal gastrinomas were removed along with 2 peripancreatic lymph node metastases. Her serum gastrin levels, which were up to $10,000 \mathrm{pg} / \mathrm{ml}$ before the operation, subsequently fell to normal values and have remained so for 9 months at present, even with secretin stimulation. Two months after the perforation, a cervical esophagogastrostomy was performed allowing restoration of oral alimentation (the colon could not be used because of previous abdominal surgery). She is currently doing well without any gastrointestinal symptoms.

\section{Discussion}

No less than 9 of 24 ZES patients referred to the University of Michigan Medical Center during the last 6 years were found to have ulcerating esophagitis. This figure (37\%) is in good agreement with findings in a previous prospective study of gastroesophageal reflux in ZES, from which it was estimated that at least one-third of such patients will develop significant esophageal disease [2]. An important observation in that study, as well as in the cases reported here, is that reflux symptoms may, in fact, be the first sign of ZES. ZES should, therefore, be kept in mind as a differential diagnosis in patients with intractable heartburn.

The importance of paying attention to esophageal involvement in ZES is emphasized by the serious complications in 3 of our patients who developed massive bleeding, severe stricture formation, and perforation, respectively. Another potential threat is the risk of malignant transformation in the Barrett's mucosa that occurs in the esophagus as a result of chronic acid reflux [3]. A most significant fact relating to esophageal disease is that patients with ZES show a high prevalence of gastroesophageal reflux despite long-term treatment with cimetidine [2]. It is also noteworthy that 2 of our patients showed progressive esophageal disease with severe complications while being on treatment with somatostatin analog for several months.

The development of serious esophageal complications despite antisecretory drug therapy emphasizes that the prime goal of treatment in patients with ZES is to eradicate the underlying gastrin-secreting tumor(s). These patients should be treated surgically as early as possible in the course of the disease, before metastases have developed [5]. A problem associated with early surgical intervention in ZES is that many gastrinomas will be too small to be localized by any of the imaging techniques that are available today; however, this problem can be reduced by percutaneous transhepatic venous sampling (PTVS) for gastrin gradient mapping of the portal drainage area. By this technique, gastrinomas measuring only $2-3 \mathrm{~mm}$ were localized in 4 of our patients [6]. We also use PTVS in the evaluation of MEN patients with ZES. Despite the morphologically diffuse nature of the pancreatic islet changes in such patients [7], the clinically significant gastrin secretion is sometimes localized to a certain region which can be removed by less-than-total pancreatectomy. It is our experience that selected MEN patients may benefit clinically by local excision of gastrinomas, even though not biochemically "cured" of their pancreatic disease [8]. Serious esophageal complications would have been prevented in one of our MEN patients by earlier referral for localization studies and exploration. After removal of 3 duodenal gastrinomas along with 2 lymph node metastases, her serum gastrin levels-which were up to $10,000 \mathrm{pg} / \mathrm{ml}$ before the operation-fell to normal values and have remained so for 9 months at present, even with secretin stimulation.

In conclusion, this study shows that significant esophageal involvement by acid-induced disease is common in ZES and may cause serious complications. Gastroesophageal reflux is not eliminated by antisecretory drugs in these patients, and it is emphasized that the prime goal of the treatment is to remove the underlying gastrin-secreting tumor(s) as early as possible in the course of the disease, before metastases develop.

\section{Résumé}

Nous avons entrepris cette étude pour établir la fréquence de participation oesophagienne dans le syndrome de ZollingerEllison. Pour une série de 24 patients présentant cette maladie, $9(37 \%)$ avaient à l'endoscopie des lésions oesophagiennes dues à l'acidité allant de l'érosion inflammatoire à l'ulcération avec saignement important, sténose sévère, et perforation. Dans 3 cas, une oesophagite importante était connue 1-5 ans avant que la maladie sous-jacente soit diagnostiquée. Des complications oesophagiennes sévères se sont produites malgrè le traitement antisécrétoire. Nous insistons sur le fait que le meilleur moyen de limiter ces complications est d'exciser chaque fois que possible la ou les tumeurs sous-jacentes sécrétant la gastrine. 


\section{Resumen}

El presente estudio fue emprendido con el propósito de determinar la frecuencia de afección ácido péptica significativa del esófago en pacientes con síndrome de Zollinger-Ellison. En una serie de 24 pacientes consecutivos con esta enfermedad, 9 (37\%) exhibieron evidencia endoscópica de lesiones esofágicas inducidas por ácido, las cuales variaron entre inflamación erosiva y ulceración con sangrado masivo, estrechez severa, y perforación. En 3 pacientes se conocía la existencia de esofagitis severa entre 1 y 5 años antes del diagnóstico de la enfermedad de base. Se desarrollaron graves complicaciones esofágicas a pesar del tratamiento con drogas antisecretorias en 3 pacientes. Se hace enfasis en que la mejor manera de disminuir tales complicaciones es mediante la resección del tumor(es) secretor de gastrina, cuando ello sea posible.

\section{References}

1. McCallum, R.W., Walsh, J.H.: Relationship between lower esophageal sphincter pressure and serum gastrin concentration in
Zollinger-Ellison syndrome and other clinical settings. Gastroenterology 76:76, 1979

2. Richter, J.E., Pandol, S.J., Castell, D.O., McCarthy, D.M.: Gastroesophageal reflux disease in the Zollinger-Ellison syndrome. Ann. Intern. Med. 95:37, 1981

3. Karl, T.R., Pindyck, F., Sicular, A.: Zollinger-Ellison syndrome with esophagitis and Barrett mucosa. Am. J. Gastroenterol. 76:611, 1983

4. Agha, F.: Esophageal involvement in Zollinger-Ellison syndrome. Am. J. Roentgenol. 144: 721, 1985

5. Wolfe, M.M., Jensen, R.T.: Zollinger-Ellison syndrome. Current concepts in diagnosis and treatment. N. Engl. J. Med. 317:1200, 1987

6. Thompson, N.W., Vinik, A.I., Eckhauser, F.E.: Microgastrinomas of the duodenum: A cause of failed operations for the ZollingerEllison syndrome. Ann. Surg. 209:396, 1989

7. Thompson, N.W., Lloyd, R.V., Nishiyama, R.H., Vinik, A.I., Strodel, W.E., Allo, M.D., Eckhauser, F.E., Talpos, G., Mervak, T.: MEN I pancreas: A histological and immunohistochemical study. World J. Surg. 8:561, 1984

8. Thompson, N.W., Bondeson, A.-G., Bondeson, L., Vinik, A.I.: The surgical treatment of gastrinoma in MEN I syndrome patients. Surgery $106: 1081,1989$

\section{Invited Commentary}

\author{
Stanley R. Friesen, M.D. \\ Department of Surgery, The University of Kansas Medical Center, \\ Kansas City, Kansas, U.S.A.
}

Years ago, Lester Dragstedt often made a comment that "man does not readily digest his own stomach." Yet those areas at either end of the stomach, the esophagus and duodenum, more easily yield to acid-peptic ulceration. The esophagus, in particular, is protected by a lower esophageal sphincter (LES) and a tough squamous and mucous lining. Another surgeon-physiologist, Alan Thal, demonstrated experimentally that the squamous epithelium of the cat's esophagus succumbed by erosion-ulceration within 20 minutes to the dripping of human gastric juice on it. It is not too surprising that the marked gastric acid hypersecretion that is one of the cardinal features of the Zollinger-Ellison syndrome (ZES), which causes ulceration as far distant as the jejunum, might also wreak havoc in the esophagus.

It is important that the authors emphasize the occurrence of esophageal complications in the ZES; the gamut of symptoms and pathological changes in the esophagus are easily overlooked, being frequently overshadowed by the abdominal findings, unless upper endoscopy is routinely done. The intermittent healing of erosive esophagitis and ulceration, with or without receptor-blockade treatment, may result in stricture formation that can be rigidly diffuse along the whole esophagus; this makes oral alimentation (and the obtaining of gastric acid for analyses) impossible.

The exact mechanism of the pathophysiology of esophageal involvement is not clear; the authors do not enlighten us on that point, although by implication they seem to point the finger at the action of the hypergastrinemia, per se, on the LES and/or the esophagus. This they support by their observations that reflux and esophagitis occur with hypergastrinemia even when patients are presumed to have a measure of control of acid hypersecretion while being treated with receptor-blockade and/ or a somatostatin analogue. It is known that gastrin in pharmacologic doses or with supraphysiologic circulating levels causes contraction of the LES. Teleologically, this would appear to constitute a protective mechanism for the esophagus. On the other hand, the normal sustained tonic contraction of the LES is mediated by intracellular calcium in the sphincter muscle that can be influenced by the inhibitory relaxing action of the neurotransmitter, vasoactive intestinal peptide (VIP) from the myenteric plexus. This effect is secondary to the muscarinic action of cholinergic receptors. In patients with esophagitis, the pressure at the LES is reduced, allowing reflux due to spontaneous relaxation. This is associated with an increased density of VIP-containing neurones in the sphincter of these patients. In ZES patients with hypergastrinemia, it is more reasonable to invoke other mechanisms for the occurrence of esophageal complications, one of which is the massive hypersecretion of gastric acid that simply overwhelms sphincter and mucous protection. Furthermore, duodenal ulceration in these patients frequently results in gastric outlet obstruction due either to duodenal narrowing or pylorospasm, both of which lead to gastric regurgitation into the esophagus.

There are some clinical observations that suggest yet a third pathophysiologic mechanism for the development of esophageal dysfunction. There are at least 2 patients who have unaccountably developed incapacitating regurgitation, without mechanical obstruction, after total gastrectomy, which certainly abolishes acid secretion and the lower esophageal sphincter as well. In one of these patients who had had a total gastrectomy for hepatic metastatic gastrinomas with persistently marked hypergastrinemia, this debilitating complication developed postoperatively for the first time. There was no anastomotic obstruction and the regurgitation persisted even after surgical revision of the Roux-en-Y esophagojejunostomy 